\title{
SERUM TRIGLYCERIDES AND TOTAL CHOLESTEROL LEVELS AND ITS RELATION WITH TYPE 2 DIABETES MELLITUS
}

\author{
YEASMIN N ${ }^{1}$, AKHTER QS ${ }^{2}$, MAHMUDA $\mathrm{S}^{3}$, AFROZ $\mathrm{R}^{4}$, NAHAR $\mathrm{S}^{5}$, HABIB TB ${ }^{6}$, ABIRA M ${ }^{7}$, \\ HOSSAIN SZ ${ }^{8}$, RAHMAN F ${ }^{9}$, DAS $\mathrm{K}^{10}$
}

\begin{abstract}
Diabetes mellitus is one of the most widespread endocrine disorder in female and its complications are increasing all over the world, leading to life threatening medical problems like cardiovascular diseases, stroke and end stage renal diseases. A relation between hyperlipidemia and diabetes mellitus has been identified. The study was carried out to observe the serum triglycerides and total cholesterol levels its relation with type 2 diabetes mellitus in adult female subjects. This cross sectional study was conducted in the Department of Physiology, Dhaka Medical College, Dhaka, during the period of January 2011 to December 2011. A total number of sixty female subjects were selected with age ranging from 30 to 50 years. Among them 30 female subjects with diabetes were included from out-patient department of Endocrinology, Dhaka Medical College Hospital, Dhaka as study group(B) and 30 apparently healthy female were taken as control group(A) for comparison. Estimation of fasting serum triglycerides (TG) and total cholesterol (TC) levels were done by enzymatic method in the Department of Physiology, Dhaka Medical College Dhaka in both groups. Fasting serum insulin level was measured by ELISA method in the Department of Laboratory of National Institute of ENT, Dhaka and fasting blood glucose was estimated by glucose oxidase method in Department of Dhaka Medical College in both groups. Data were analyzed by Unpaired Student's- test and Pearson's correlation co-efficient (r) test as applicable. The value of fasting serum TG and TC level were significantly higher in study subjects than those of control. In study subjects fasting serum TG and fasting serum TC levels showed positive correlation with fasting blood glucose and serum insulin level.
\end{abstract}

Conclusion: Present study revealed that fasting serum triglyceride (TG) and fasting serum cholesterol (TC) levels have positive relationship with fasting serum insulin and fasting blood glucose levels.

Key words: Fasting serum insulin, fasting blood glucose, fasting serum triglyceride and fasting serum cholesterol levels, diabetes mellitus.

J Dhaka Med Coll. 2018; 27(2) : 148-154

\section{Introduction}

Diabetes mellitus (DM) is a metabolic disorder characterized by chronic hyperglycemia with disturbances of carbohydrate, fat and protein metabolism resulting from defects in insulin secretion and / or insulin action. ${ }^{1}$ Diabetes mellitus (DM) is one of the common noncommunicable diseases and it is one of the most challenging health problems in the $21^{\text {st }}$ century. $^{2}$ There are two general types of diabetes mellitus, one is type 1 or insulin dependent DM (IDDM) and other is type 2 or non-insulin

1. Dr. Nahid Yeasmin, Assistant Professor, Department of Physiology, Dhaka Medical College, Dhaka.

2. Dr. Qazi Shamima Akhter, Professor \& Head, Department of Physiology, Dhaka Medical College, Dhaka

3. Dr. Sayeeda Mahmuda, Associate Professor (CC), Department of Pathology ,National Institute of Ophthalmology \& Hospital, Sher-E-Bangla Nagar, Dhaka.

4. Dr. Romana Afroz Assistant Professor, Department of Pharmacology, Dhaka Medical College, Dhaka.

5. Dr. Sharmin Nahar, Lecturer, Department of Physiology, Dhaka Medical College

6. Dr. Tamanna Binte Habib, Lecturer, Department of Physiology, Dhaka Medical College, Dhaka

7. Dr. Mahmuda Abira,M phil student ,Department of Physiology, Dhaka Medical College, Dhaka

8. Dr. Syed Zakir Hossain, Associate Professor, Department of Medicine, Dhaka Medical College, Dhaka

9. Dr. Farhana Rahman, Lecturer, Department of Physiology, Dhaka Medical College, Dhaka

10. Dr. Konica Das, Lecturer, Department of Physiology, Dhaka Medical College,

Correspondence : Dr. Nahid Yeasmin, Assistant Professor, Department of Physiology, Dhaka Medical College, Dhaka, Tel: 01923619159 
dependent DM. Among them, type 2 diabetes mellitus is more common and about 90 to $95 \%$ of all cases of diabetes mellitus. ${ }^{3}$ Type 2 diabetes mellitus and its prevalence has increased continuously over past decades. Rapid economic growth, increased life expectancy and altered life style have significantly increased the prevalence of type 2 diabetes mellitus. The chronic hyperglycemia of diabetes is associated with long term dysfunction, damage and failure of various organs especially the eyes, kidney, nerves, heart and blood vessels ${ }^{4}$.According to American Diabetes Association, diagnostic criteria of diabetes mellitus are fasting blood glucose e" $7.0 \mathrm{mmol} / 1$ or 2 hours after $75 \mathrm{gm}$ glucose e" $11.1 \mathrm{mmol} / 1$ or random blood glucose e" $11.1 \mathrm{mmol} / 1$ or HbA1c e" $6.5 \% .{ }^{5}$ According to International Diabetic Federation (IDF), about 24.4 million diabetic people in the USA, 65.1 million in India and 5.1million in Bangladesh. This number is gradually increasing day by day will rise to 592 million by the year 2035 representing about $8.8 \%$ of the world population. By the year 2035, the number of diabetic people will be about 29.7 million in USA, 109.2 million in India and 16.8 million in Bangladesh. ${ }^{6}$ In each year about $5 \%$ of all death are caused by diabetes mellitus globally ${ }^{7}$. Hyperlipidemia is the most important risk factor for premature cerebrovascular disease, stroke and peripheral vascular disease ${ }^{8}$. Hyperlipidemia is stands for abnormal elevation of various lipids and lipoprotein in the blood thus leading to atherosclerosis of arteries, especially in the aorta, coronaries, carotids and cerebral arteries. Hypercholesterolemia and hypertriglyceridemia both of which constitute major risk factor for cardiovascular diseases 9 .

Hyperlipidemia account for an estimated 54\% of all strokes and $50 \%$ of all ischemic heart diseases ${ }^{10}$. A study in the USA found approximately one in every six adult has hyperlipidemia or high cholesterol in their blood. People with high cholesterol have twice the risk for heart disease than people with lower level of cholesterol but they are unaware of this condition because there are no symptoms ${ }^{11}$.

Hyperlipidemia is very common in type 2 diabetes mellitus. Prevalence of hyperlipidemia in type $2 \mathrm{DM}$ is $64-75 \%$. The risk of cardiovascular disease and cardiovascular mortality is significantly increased in patient with type 2 diabetes mellitus relative to healthy individual. Lipid abnormalities observed in type $2 \mathrm{DM}$ are not only quantitative, but also qualitative and kinetic in nature. A number of factors may contribute to the change in lipid metabolism in type $2 \mathrm{DM}$, including insulin resistance and/ or relative insulin deficiency, adipocytokines (Adiponectin) and hyperglycemia $^{12}$.

Insulin resistance represents the earliest detectable abnormality in of type 2 diabetes mellitus and is one of the major underlying mechanisms of hyperlipidemia and cardiovascular diseases. ${ }^{13}$ Insulin is the most potent anabolic hormone which is secreted by beta cells of pancreatic islets of Langerhans. Insulin has important role in lipoprotein metabolism and the effects of insulin on lipoprotein metabolism are: insulin inhibits hormone-sensitive lipase, inhibits hepatic triglyceride rich VLDL production, activates lipoprotein lipase and increases low density lipoprotein (LDL) receptor protein expression on the plasma membrane ${ }^{14},{ }^{15}$.

A number of studies have shown the relationship between hyperlipidemia and insulin resistances in type- 2 diabetes mellitus and they suggested that insulin resistance or insulin deficiency affects key enzymes and pathways in lipid metabolism. In particular, the following processes are affected: Apo protein production, regulation of lipoprotein lipase, action of cholesteryl ester transfer protein and hepatic and peripheral actions of insulin. ${ }^{16}$

Again some researcher suggested that lower level of adiponectin (secreted from adipose tissue) are associated with insulin resistance play an important role in development of hyperlipidemia in type 2 diabetes mellitus. Lower level of adiponectin are positively associated with triglyceride and total cholesterol levels ${ }^{17}$.

A study was done in Western Europe and they found that at least one-third of the population with type 2 diabetes mellitus have hyperlipidemia and patient with hyperlipidemia 
also show evidence of diabetes mellitus. Thus type 2 diabetes mellitus and hyperlipidemia are common intertwined condition that shares a significant overlapping risk factors and complications. They suggest that higher triglycerides has a link for development of central obesity and insulin resistance and both are important factors for development of cardiovascular diseases ${ }^{18,}, 19$.

Some studies have been done on this regard in abroad but no published data has yet been available on this aspect in our country. Therefore, the present study has been designed to observe the serum TG and TC levels and its relation with type 2 diabetes mellitus in adult female. Better understanding of these metabolic changes with hyperglycemia will help in the detection of women at risk for future cardiovascular diseases and renal diseases. Treatment and preventive measure can reduce the risk of developing cardiovascular diseases and thus reduce burden on our health budget

\section{Methods}

This cross sectional study was conducted in the department of Physiology, Dhaka Medical College, Dhaka, during the period of January 2011 to December 2011. Thirty females of 3050 years age range with type 2 diabetes mellitus were included in this study as study (B) group. They were selected from the out-patient department of Endocrinology of Dhaka Medical College Hospital, Dhaka. Age matched thirty apparently healthy females were taken as control (A) group for comparison. Subjects having history of heart, liver, kidney diseases, endocrine disorders and women taking hormone replacement therapy, steroid, alcohol user, and smoker were excluded from the study. After selection of subjects, the objectives, nature, purpose and benefit of the study were explained to the subjects in detail. Written informed consent was taken from the participants. They were encouraged for voluntary participation. They were also allowed to withdraw themselves from the study whenever they feel like. Ethical permission was taken from ethical committee of Dhaka Medical College. Detailed medical history, menstrual history and family history of the subjects were taken and recorded in a pre-designed data collection form. The subjects were advised to attend the laboratory in the department of Physiology of Dhaka Medical College, Dhaka between 8AM to 10AM in fasting state. Then with all aseptic precautions $5 \mathrm{ml}$ of venous blood was drawn from antecubital vein by disposable plastic syringe. Blood was allowed to clot and then centrifuged at rate of $3000 \mathrm{rpm}$ and supernatant clear serum was separated. Serum was taken in eppendrof tube and was preserved in refrigerator. Fasting serum insulin level was assessed by Enzyme Linked Immunosorbent Assay (ELISA) method in the laboratory of National Institute of ENT, Dhaka and fasting blood glucose level was estimated by glucose oxidase method in the laboratory of Physiology of Dhaka Medical College, Dhaka. Fasting serum TG and fasting TC level were estimated by enzymatic method in the laboratory of Physiology of Dhaka Medical College, Dhaka. Statistical analysis was done by Unpaired Student's t- test. Correlation was analyzed by Pearson's correlation co-efficient (r) test. P value $<0.05$ was taken as of significance.

\section{Results}

In this study the mean $( \pm \mathrm{SD})$ of serum TG level was $99.93 . \pm 32.37 \mathrm{mg} / \mathrm{dl}$ in group $\mathrm{A}$ and $238.77 \pm 85.05 \mathrm{mg} / \mathrm{dl}$ in group B. The level of serum TG was significantly higher in group B than that of control and the result was statistically significant $(p<0.001)$. $)$. The mean $( \pm \mathrm{SD})$ of serum TC was $130.20 \pm .41 .33 \mathrm{mg} / \mathrm{dl}$ in group A and $226 . \pm 35.24 \mathrm{mg} / \mathrm{dl}$ in group B. The level of TC was significantly higher in group B than that of control and the result was statistically significant $(\mathrm{p}<0.001)$ (Table-I).

The mean $( \pm \mathrm{SD})$ of fasting serum insulin level was $5.76 \pm 3.27 \mathrm{~mm} / \mathrm{Hg}$ in group $\mathrm{A}$ and $20.58 \pm 6.57 \mathrm{uIU} / \mathrm{ml}$ in group B. The level of serum insulin was significantly higher in group $B$ than that of control and the result was statistically significant $(\mathrm{p}<0.001)$. The mean $( \pm \mathrm{SD})$ of fasting blood glucose level was $5.08 \pm$ $1.25 \mathrm{uIU} / \mathrm{ml}$ in group A and 9.91. $\pm 3.32 \mathrm{uIU} /$ $\mathrm{ml}$ in group $\mathrm{B}$. The level of blood glucose was 
significantly higher in group B than that of control and the result was statistically significant $(p<0.001)$ Table-II.

Table I

Fasting serum triglyceride (TG) and Fasting serum total cholesterol (TC) in both groups

\begin{tabular}{cccc}
\hline Groups & $\mathrm{n}$ & $\begin{array}{c}\mathrm{TG}(\mathrm{mg} / \mathrm{dl}) \\
(\mathrm{Mean} \pm \mathrm{SD})\end{array}$ & $\begin{array}{c}\text { TC }(\mathrm{mg} / \mathrm{dl}) \\
(\mathrm{Mean} \pm \mathrm{SD})\end{array}$ \\
\hline A & 30 & $99.93 \pm .32 .37$ & $130.20 \pm .41 .33$ \\
B & 30 & $238.77 \pm .85 .05$ & $226 . \pm 35.24$ \\
\hline
\end{tabular}

Statistical analysis

\begin{tabular}{lcc}
\hline Groups & $\begin{array}{c}\text { TG } \\
(\mathrm{p} \text { value })\end{array}$ & $\begin{array}{c}\text { TC } \\
(\mathrm{p} \text { value })\end{array}$ \\
\hline A vs B & $0.001^{* * *}$ & $0.001^{* * *}$ \\
\hline
\end{tabular}

Unpaired Student's't' test was performed to compare between groups. The test of significance was calculated and $p$ values $<0.05$ was accepted as level of significance.

Group A $\quad$ Healthy adult female
$\mathrm{n}=$ Number of subjects

Group B : $\quad$ subjects with hyperlipidemia $* / * * * * *=$ Significant

\section{Table II}

Fasting serum insulin (FSI) and Fasting blood glucose (FBG) in both groups

\begin{tabular}{cccc}
\hline Groups & $\mathrm{n}$ & $\begin{array}{c}\text { FSI }(\mathrm{uIU} / \mathrm{ml}) \\
(\mathrm{Mean} \pm \mathrm{SD})\end{array}$ & $\begin{array}{c}\text { FBG }(\mathrm{mmol} / \mathrm{L}) \\
(\mathrm{Mean} \pm \mathrm{SD})\end{array}$ \\
\hline A & 30 & $5.76 . \pm 3.27$ & $5.08 \pm .1 .25$ \\
B & 30 & $20.58 \pm 6.57$ & $9.91 \pm .3 .32$ \\
\hline
\end{tabular}

Statistical analysis

GroupsFSI ( $\mathrm{p}$ value)FBG ( $\mathrm{p}$ value)

A vs B0.001*** $0.001^{* * *}$

Unpaired Student's't' test was performed to compare between groups. The test of significance was calculated and $p$ values $<0.05$ was accepted as level of significance.
Group A : Healthy adult female
$\mathrm{n}=$ Number of subjects
Group B : Diabetic adult female
$* /^{* *} / * *=$ Significant

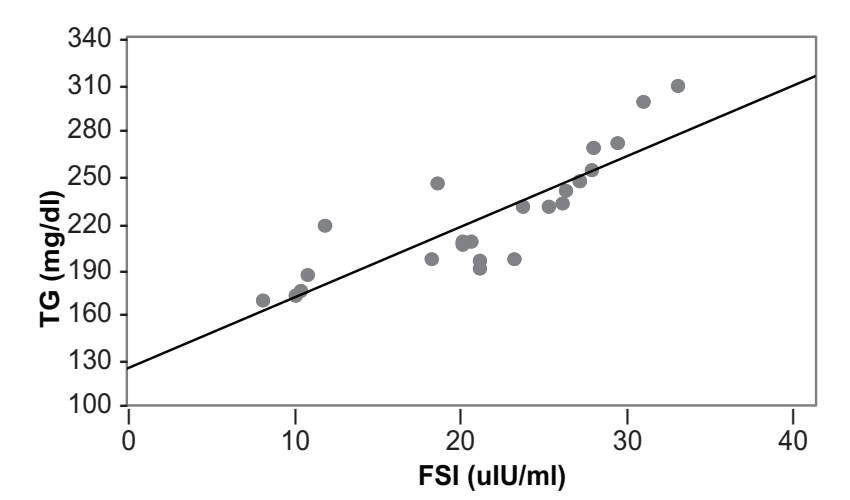

Fig.-1: Correlation of Serum TG with FSI in study group $(n=30)$

$\mathrm{n}=$ number of subjects in study group;

$\mathrm{r}=0.858 ; \mathrm{p}<0.001$

Serum fasting TG level showed positive correlation $(r=0.858)$ with fasting serum insulin level in study group and result was statistically significant. Again serum TG level showed positive correlation $(\mathrm{r}=0.983)$ with fasting blood glucose level in study group and result was also statistically significant. Table- III and Figure-1, 2.

\section{Table-III}

Correlation of fasting serum triglycerides level with FSI and FBG in study group (B)

\begin{tabular}{lcc}
\hline Parameters & \multicolumn{2}{c}{ Group B $(\mathrm{n}=30)$} \\
\cline { 2 - 3 } & $\mathrm{r}$ & $\mathrm{p}$ \\
\hline Fasting serum insulin (FSI) & +0.858 & 0.001 \\
Fasting blood glucose (FBG) & +0.983 & 0.001 \\
\hline
\end{tabular}

Pearson's correlation coefficient $(r)$ test was performed to compare relationship between parameters. The test of significance was calculated and $p$ value $<0.05$ was accepted as level of significance.

Again, fasting serum TC level showed positive correlation ( $\mathrm{r}=652)$ with serum insulin level and also showed positive correlation (0.815) with fasting blood glucose level in study group and result was statistically significant. Table-IV and Figure 3, 4. 


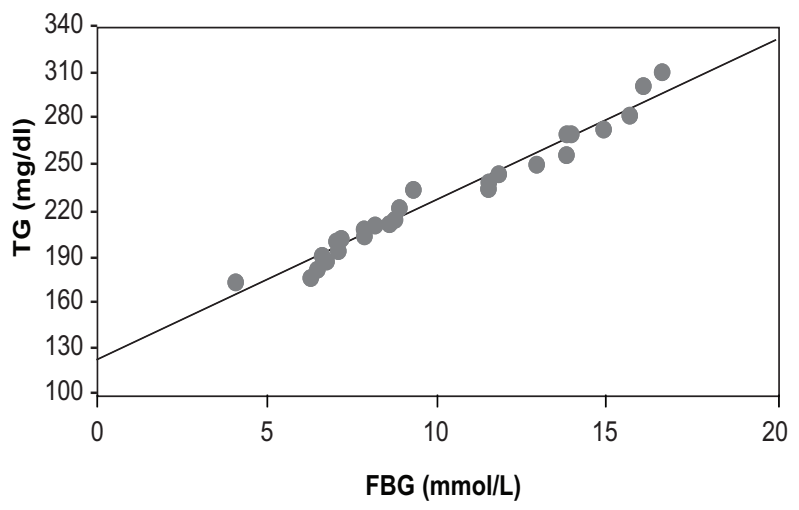

Fig.-2: Correlation of Serum TG with FBG in study group $(n=30)$

$\mathrm{n}=$ number of subjects in study group;

$\mathrm{r}=0.983 ; \mathrm{p}<0.001$

Table IV

Correlation of serum total cholesterol (TC) level with FSI and FBG in study group

\begin{tabular}{lcc}
\hline Parameters & \multicolumn{2}{c}{ Group B $(\mathrm{n}=30)$} \\
& $\mathrm{r}$ & $\mathrm{p}$ \\
\hline Fasting serum insulin & +0.652 & 0.001 \\
Fasting blood glucose & +0.815 & 0.001 \\
\hline
\end{tabular}

Pearson's correlation coefficient $(r)$ test was performed to compare relationship between parameters. The test of significance was calculated and $p$ value $<0.05$ was accepted as level of Significance.

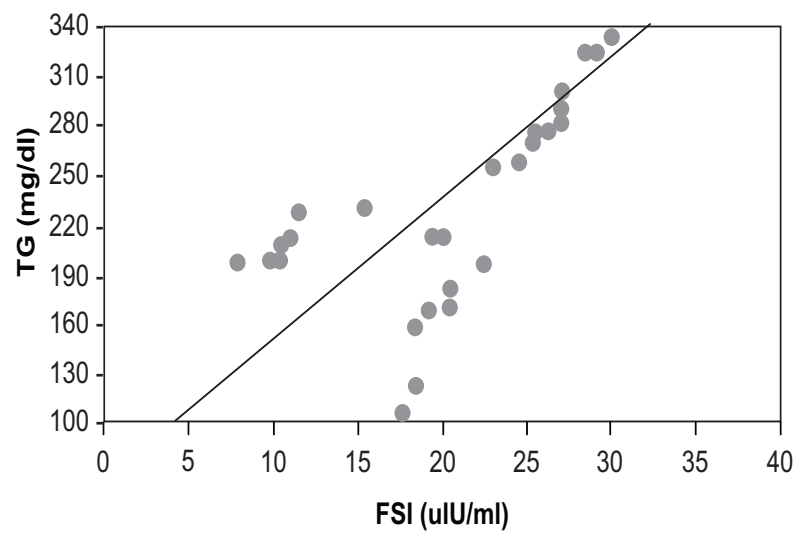

Fig.-3: Correlation of Serum TC with FSI in study group $(n=30)$

$\mathrm{n}=$ number of subjects in study group;

$\mathrm{r}=0.652 ; \mathrm{p}<0.001$

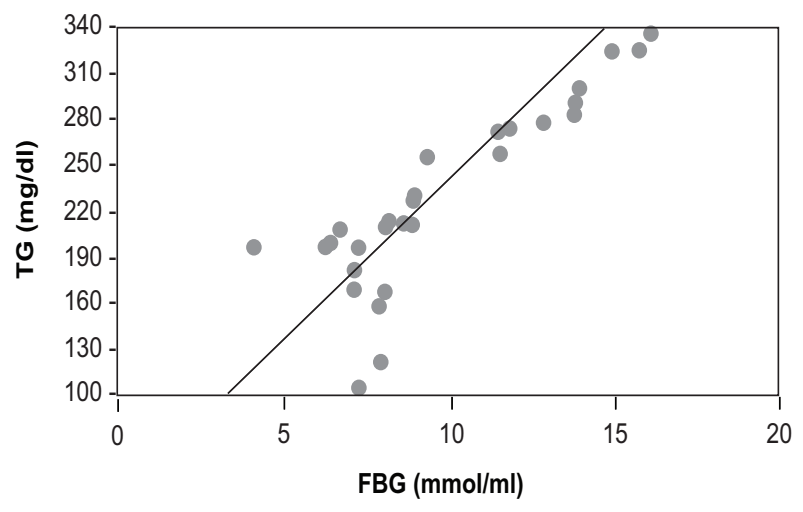

Fig.-4: Correlation of Serum TC with FBG in study group $(n=30)$

$\mathrm{n}=$ number of subjects in study group;

$\mathrm{r}=0.815 ; \mathrm{p}<0.001$

\section{Discussion}

In the present study, the values of fasting triglyceride (TG) and total cholesterol (TC) in controls were almost within normal range and also similar to reported by the several investigators from abroad ${ }^{8-11}$

In this study, triglyceride (TG) in study group was higher than that of controls and result was statistically significant. Similar types of observations were found by other workers, $10-$ 13. TC in study subjects were also higher than those of controls and result was statistically significant. Similar types of findings were reported by different researchers of different countries $8 ., 11,12$ On the contrary, similar observations were made by other researcher but they did not find any significant difference in TG level between the groups. It suggested that it may be due to different type of nutrition and life style in their study population. ${ }^{10}$

Again, correlation analysis showed positive correlation of serum TG level with fasting serum insulin and fasting blood glucose. In addition, serum TC level also showed positive correlation with fasting serum insulin and fasting blood glucose. The results were statistically significant. Similar observations were also reported by some investigators. ${ }^{16}$

The exact possible mechanisms regarding these observed effects cannot be revealed directly from present study. However, several investigators of different countries proposed various 
suggestions on these aspects, which might be causes of our present findings. It has been suggested that lipid metabolism in type 2 diabetes mellitus is modulated by series of factors among which insulin resistance is the most prominent feature. Insulin resistance is the pathophysiologic mechanism of diabetic hyperlipidemia. Insulin resistance in adipose tissue causes increased activity of hormone sensitive lipase resulting in increased levels of circulating fatty acids. These fatty acids are carried to the liver where they are converted to triacylglycerol and cholesterol ${ }^{20}$. Again in insulin resistance state, the assembly and secretion of triglyceride rich lipoprotein is increased due to decreased Apo lipoprotein B (apoB) degradation and increased the expression of the microsomal transfer protein (MTP) in the liver and both of these factors help in overproduction of VLDL-TG and VLDL-Apo B. So TG and total TC levels are increased in blood $^{21}$.

In addition in diabetic patient due to insulin resistance, the apoprotein CIII synthesis is also increased. This apolipoprotein has two properties that causes retention of TGS in the circulation. First, apoprotein C-III interfere with the action of lipoprotein lipase, the enzyme responsible for hydrolysis of VLDL triglyceride. Second, apolipoprotein C-III interfere the uptake of TG rich VLDL remnant by receptor on liver cells. So triglycerides level are increase in circulation. ${ }^{22}$

Moreover, adiponectin (a hormone secreted from adipose tissue) increases the activity of lipoprotein lipase and also increases the catabolism of triglyceride rich VLDL and chylomicron particles. But in type 2 Diabetes mellitus due to insulin resistance, adiponectin production are decrease. So decreased level of adiponectin also decreased the catabolism of TG rich particles and increased the level of triglycerides ${ }^{23-25}$. Furthermore, insulin resistance are associated with some inflammatory cytokines namely leptin, tumor necrosis factor (TNF-á), transforming growth factor (TGF-â), IL-6, which are responsible for overproduction of TG and TC in blood. TNF-á and IL- 6 increases the hepatic production of 3hydroxy-3 methyl glutaryl coenzyme A (HMG$\mathrm{COA}$ ) reductase, is an important for cholesterol biosynthesis. Thereby increases the synthesis of cholesterol. ${ }^{26}$

\section{Conclusion}

From this study, it can be concluded that hyperlipidemia, which is characterized by higher levels of fasting serum TG and TC level present in study group, may be due to high level of serum insulin and blood glucose levels.

\section{Acknowledgement}

The authors are thankful to the study subjects for their active, sincere and voluntary participation. The authors are also grateful to the Department of Physiology and Department of Endocrinology for their kind support.

\section{References}

1. Pooja Maharjan, Dipendra Raj Pandey, Govardhan Joshi, Sakrita Hona, Bibek Bhatta, Alneli M. Glycated Hemoglobin(HBA1C) is a predictor of dyslipidemia in type 2diabetes Nepalese patient. International Journal of an advanced research.2017; 5(2):113-121.

2. Ahmed.KA, Muniandy S, Ismail IS. Type 2 diabetes and vascular complication: A pathophysiological view. Biomed Res. 2010; 21 (2): 147-155.

3. Hall, JE.Text Book of Medical Physiology. $12^{\text {th }}$ ed. India: Elsvier Inc; 2011.939-940.

4. Amit Kumar Dixit, Ranjit Dey, Aela Suresh, Siddhartha Chaudhuri, Ashok kumar Pande, Achintya Mitra. The prevalence of Dyslipidemia in patients with diabetes mellitus of Ayureveda Hospital. Journal of Diabetes \& Metabolic Disorders.2014; 13(58): $1-6$

5. American Diabetes Association. Classification and Diagnosis of Diabetes. Diabetes care.2015; 38(1): 8-16.

6. Guariguata .L, Whiting. DR, Hambleton I. Global estimates of diabetes prevalence for 2013 and projections for 2035. Diabetes Res Clin Pract. 2013; 103(2014): 137-149.

7. IDF Diabetes Atlas. $6^{\text {th }}$ ed. Brussels, Belgium: International Diabetes Federation; 2013;2:1-12.

8. Bruno Verges. Pathophysiology of Diabetic dyslipidemia: Where are we? Diabetologia.2015; 58(1):886-902.

9. Mercurio V, Carlomango G, Fazio V \& Fazio S. Insulin resistance is it time for primary prevention? World $\mathrm{J}$ Cardiol.2012; 4(1):1-7.

10. Pessin. JH \& Sal. Signatiel AR. Signaling pathways in insulin action: molecular targets of insulin resistance. J Clin Ivest.2000; 106(2):64-69. 
11. Klause G Parhofer. Pathophysiology of diabetic dyslipidemia: Implications for atherogenesis and treatment. Clinical Lipidology.2011; 6(1):401-410.

12. Ronald M. Krauss. Lipids and Lipoproteins in patients with type 2 diabetes. Diabetes Care. 2004; 27(1):1496-1503.

13. Ira j. Goldberg. Diabetic Dyslipidemia: Causes and Consequences. The journal of clinical Endocrinology and Metabolism.2001; 86(3):965-971.

14. Guang-yu Chen,Lui Li, Fei Dai, Xing-jian Li, Xiaoxin xu. Prevalence of and risk factors for type 2 diabetes mellitus in hyperlipidemia in China. Med Sci Monit.2015; 21 (1):2476-2484.

15. Clay F. Semenkovich. Insulin resistance and atherosclerosis. J Clin. Invest. 2006; 116(1):18131822 .

16. Prashant Regmi, Prajwali gyawali, Rojeet Shresthaa, Manoj Sigdel,Kisun D Mehta, Shanker Majhi. Pattern of dyslipidemia in type 2 diabetic subjects in Eastern Nepal.JNAMLS.2009; 10(1):11-16.

17. H.A. Elnasri and A.M. Ahmed. Pattern of lipid changes among type 2diabetes patients in Sudan.Eastern Mediterranean Health journal, 2008; 14(2):314-318.

18. Thapa Subarna Dhoj, KC Shiva Raj, Gautam Santosh, Gyawali deepika. Dyslipidemia in type 2 diabetes mellitus. Journal of pathology of Nepal.2017; 7(1): 1149-1154.

19. Ramprasad Gadi, and Frederick F. Samaha. Dyslipidemia in type 2 Diabetes Mellitus. Current Diabetes Reports.2007; 7(1):228-234.

20. Champe,PC, Harhey, RA, Ferrier, DR.Lippincott's illustrated reviews: Biochemistry, $4^{\text {th }}$ ed, 2008; Wolters Kluwers, New Delhi.

21. Rafael Carmena.High Risk of lipoprotein dysfunction in type 2 diabetes mellitus. Rev Esp Cardiol Supl.2008; 8(1): 18c-24c.

23. Scott M Grundi. Hypertriglyceridemia, insulin Resistance, and the metabolic syndrome.Am J Cardiol.1999; 83(1):25-29.

24. G. A. Christou and D.N Kiortsis. Adiponectin and lipoprotein metabolism. Etiology and Pathophysiology.2013; 14(1): 939-949.

25. Liiping Qiao, Chenhui, DeneysR, Van der Westhuyen and Jianhua Shao. Adiponectin reduces plasma triglyceride by increasing VLDL triglyceride catabolism. Diabetes.2008; 57(1):1824-1833.

26. Xiong Z. Ruan. Zac varjhese, Stephen H. Dysregulation of LDL receptor under the influence of inflammatory cytokines: Anew pathway of foam cell formation. World Journal of Diabetes 2001; 60 (5):1716-1726. 